\title{
Capital Accumulation of a Firm facing an Emissions Tax ${ }^{1}$
}

\author{
Richard F. Hartl \\ Department of Economics and Management, University of Magdeburg, Germany \\ Peter M. Kort \\ Department of Econometrics and CentER, Tilburg University, The Netherlands
}

\begin{abstract}
In this paper we consider the dynamic behavior of a firm that is subject to environmental regulation. It is assumed that, in order to prevent firms from polluting the environment excessively, the government imposes an emissions tax. We determine how an emissions tax influences the firm's decisions concerning investments and abatement efforts.

In the model we incorporate the realistic property that a given abatement expenditure leads to more pollution reduction when pollution is large. This property implies increasing returns to scale with respect to pollution reduction. It turns out that, together with the „usual" assumption of decreasing returns to scale with respect to production, this property leads to the occurrence of history dependent equilibria in case the pollution tax rate is sufficiently large. It is possible to derive an explicit formula for the threshold tax rate above which these history dependent equilibria can occur. We show that an investment grant by the government can influence the firm so as to approach the equilibrium with a higher capital stock.

Finally, we compare our results with those of a related model where the firm faces a strict pollution standard rather than an emissions tax. Among other things, we show that growth is more suppressed under a tax than under a standard when the firm is small.
\end{abstract}

1) The research of the second author has been made possible by a fellowship of the Royal Netherlands Academy of Arts and Sciences. The authors like to thank two anonymous referees for their valuable comments. 


\section{Introduction}

In practice one of the most important problems of firm behavior these days is how to react to environmental regulation. The government has several policy instruments at its disposal to give the firm an incentive to reduce pollution, such as an emissions tax, a pollution permit system, or the government may influence pollution directly by setting an upper bound on the total amount of emissions that the firm is allowed to generate within a specific time period.

In this paper we try to establish the optimal investment policy of the firm, while the government imposes a tax on emissions. Our model is different from several other contributions in the specification of the pollution function. In Xepapadeas (1992) and in Kort, Van Loon, and Luptacik (1991) a given abatement expenditure leads to a certain pollution reduction, which is independent of the amount of pollution caused by the production process. This suggests that pollution can be driven to zero or can even be made negative. Indeed, in these models a constraint appears that has to keep pollution nonnegative. In our formulation we adopt the more realistic assumption that more abatement expenditures are needed to reduce pollution by a given amount when the level of pollution is already low, which implies that driving pollution to zero is very expensive, if not impossible.

In Section 2 the optimization problem of the firm is specified as an optimal control problem, while Section 3 contains the mathematical analysis. In Section 4 we present the solution in case of a relatively low emissions tax rate, while in Section 5 the same is done in case of a large tax rate. Section 6 gives some comparisons with a related model that has a pollution standard. Section 7 concludes the paper.

\section{Model Formulation}

According to Jorgenson and Wilcoxen (1990) possible firm's responses to environmental regulation are investing in abatement technology, i.e. the use of special devices to treat wastes after they have been generated, and changing the production process to reduce emissions. The first response is commonly known as end-of-pipe abatement and is often the choice when existing firms have to meet newly imposed standards. Compared to endof-pipe abatement a more modern approach is changing the production process in order to reduce emissions. The least disruptive way of doing this is to switch to cleaner inputs and it is this kind of abatement effort we choose to model here.

Consider a firm that owns a stock of capital goods $\mathrm{K}$ through which it can produce output $\mathrm{Q}(\mathrm{K})$. It is reasonable to assume that

$$
\mathrm{Q}(0)=0, \mathrm{Q}^{\prime}(\mathrm{K})>0, \mathrm{Q}^{\prime \prime}(\mathrm{K})<0
$$


The production process generates emissions $\mathrm{E}=\alpha \mathrm{Q}(\mathrm{K})$, where $\alpha$ equals the emissions to output ratio. The firm has the possibility to reduce the emissions to output ratio $\alpha$ by carrying out abatement expenditures A, i.e. $\alpha=\alpha(\mathrm{A})$ with diminishing returns to such expenditures:

$$
\alpha(\mathrm{A})>0, \alpha^{\prime}(\mathrm{A})<0, \alpha^{\prime \prime}(\mathrm{A})>0,
$$

see, e.g., Dasgupta (1982) or Van der Ploeg and Withagen (1991).

As a practical example of such abatement expenditures consider the coal industry which, according to Jorgenson and Wilcoxen (1990, p. 328), belongs to the most heavily regulated industries in the USA. It is possible to reduce sulfur dioxide emissions through substitution of expensive low-sulfur coal for cheap high-sulfur coal. The more the firm wants to reduce emissions the higher it can make the percentage of low-sulfur coal. Now, the extra cash outflow, that arises from switching from high-sulfur to low-sulfur coal, can be seen as abatement expenditures; see Jorgenson and Wilcoxen (1990, p. 317).

Note that $\mathrm{A}=0$ is associated with the production technology that would be chosen by a profit maximising firm in absence of any environmental regulations. Hence the emissions to output ratio associated with this technology is $\alpha(0)$.

In order to prevent the unrealistic scenario that involves zero pollution we further impose that

$$
\lim _{\mathrm{A} \rightarrow \infty} \alpha^{\prime}(\mathrm{A})=0 .
$$

Of course, abatement expenditures are always non-negative:

$$
\mathrm{A} \geq 0 .
$$

The available instruments for the implementation of environmental policy can take the form of exogenously determined emissions charges or direct controls on emissions levels. The case of emissions standards has already been considered in Hartl and Kort (1994). Here we deal with the instrument of an emissions tax; see Pigou (1920). Let $\tau>0$ be the tax per unit of emissions. Then the total amount paid by the firm at each instant of time is

$$
\tau \alpha(\mathrm{A}) \mathrm{Q}(\mathrm{K}) .
$$

The capital stock can be increased by productive investments I where investment cost equal C(I) for which we assume

$$
\mathrm{C}(0)=0, \quad \mathrm{C}^{\prime}(\mathrm{I})>0, \quad \mathrm{C}^{\prime \prime}(\mathrm{I})>0 .
$$


Investment cost consists of cost of acquisition and internal cost of adjustment. The latter cost can arise due to, e.g., stopping the production line to install new machines, or stresses imposed upon the managerial and administrative capabilities of existing staff.

Without productive investments the capital stock decreases by depreciation at rate a.

We assume that the firm is "small", i.e., the product can be sold on the market against a fixed market price $\left.{ }^{2}\right) \mathrm{p}$, and that abatement expenditures face a horizontal supply curve so that also their unit price is constant and equal to, say, v.

For reasons of convenience (to avoid some cumbersome analysis) we only consider the case that the selling price $\mathrm{p}$ exceeds the per product emissions tax even when no abatement efforts are performed:

$$
\mathrm{p}-\tau \alpha(0)>0
$$

With the parameters

$$
\begin{aligned}
& \text { a ... depreciation rate }(a>0) \text {, } \\
& \text { r ... discount rate }(r>0),
\end{aligned}
$$

and after assuming that the firm maximizes discounted cash flows over an infinite planning period, we obtain the following dynamic model of the firm:

$$
\begin{aligned}
& \max _{\mathrm{I}, \mathrm{A}} \int_{0}^{\infty} \mathrm{e}^{-\mathrm{rt}}\{\mathrm{pQ}(\mathrm{K})-\mathrm{vA}-\mathrm{C}(\mathrm{I})-\tau \alpha(\mathrm{A}) \mathrm{Q}(\mathrm{K})\} \mathrm{dt} \\
& \text { s.t. } \quad \dot{\mathrm{K}}=\mathrm{I}-\mathrm{aK}, \quad \mathrm{K}(0)=\mathrm{K}_{0} \\
& \qquad \mathrm{~A} \geq 0
\end{aligned}
$$

\section{Mathematical Analysis and Economic Interpretations}

Since the control A does not enter the system dynamics (8) this model can be treated by applying a two step approach (cf. Hartl, 1988):

\subsection{The Step 1 Problem}

To find the optimal level of abatement expenditures for a given $\mathrm{K}$, we solve the following static (Step 1) problem:

2) The results would be the same, qualitatively spoken, if the firm has some market power, i.e., $\mathrm{p}=\mathrm{p}(\mathrm{Q}), \mathrm{p}^{\prime}>0, \mathrm{p}^{\prime \prime}<0$ and if the revenue function $\mathrm{R}(\mathrm{Q})=\mathrm{Qp}(\mathrm{Q})$ is concave. 


$$
\max _{\mathrm{A}}\{-\mathrm{vA}-\tau \alpha(\mathrm{A}) \mathrm{Q}(\mathrm{K})\}
$$

s. t.

$$
\mathrm{A} \geq 0
$$

The solution is easily obtained by using the Kuhn Tucker conditions:

$$
\begin{aligned}
& \mathrm{L}=-\mathrm{vA}-\tau \alpha(\mathrm{A}) \mathrm{Q}(\mathrm{K})+\mu \mathrm{A} \\
& \mathrm{L}_{\mathrm{A}}=-\mathrm{v}-\tau \alpha^{\prime}(\mathrm{A}) \mathrm{Q}(\mathrm{K})+\mu=0
\end{aligned}
$$

as well as $\mu \geq 0$ and $A \mu=0$. This yields

$$
A(K)=\left\{\begin{array}{l}
0 \\
A_{\tau}(K)
\end{array}\right\} \text { when }\left\{\begin{array}{l}
-\alpha^{\prime}(0) Q(K) \leq v / \tau \\
-\alpha^{\prime}(0) Q(K)>v / \tau
\end{array}\right\} \text { i.e. } \quad K\{\leq\} \tilde{K},
$$

where $A_{\tau}(K)$ is an implicit function such that

$$
-\tau \alpha^{\prime}(\mathrm{A}) \mathrm{Q}(\mathrm{K})=\mathrm{v},
$$

and $\tilde{\mathrm{K}}=\tilde{\mathrm{K}}(\tau)$ is the largest capital stock, for which it is optimal to have zero abatement:

$$
-\tau \alpha^{\prime}(0) Q(\tilde{\mathrm{K}})=\mathrm{v} \text { i.e. } \tilde{\mathrm{K}}=\mathrm{Q}^{-1}\left(-\mathrm{v} / \tau \alpha^{\prime}(0)\right) .
$$

We see that abatement expenditures are zero when the capital stock is low. This makes sense, because then the decrease in pollution due to a reduction of the emissions to output ratio is limited, so that carrying out abatement expenditures does not lead to a severe reduction of the emissions tax to be paid by the firm. From equation (14) it can be easily derived that abatement expenditures decrease with their purchase price, and are increasing in the emissions tax rate, as can be expected.

From the implicit function theorem one can compute the derivatives of $A_{\tau}(K)$ for $K>\tilde{K}$ :

$$
\begin{aligned}
& \mathrm{A}_{\tau}^{\prime}(\mathrm{K})=-\frac{\alpha^{\prime} \mathrm{Q}^{\prime}}{\alpha^{\prime \prime} \mathrm{Q}}>0,
\end{aligned}
$$

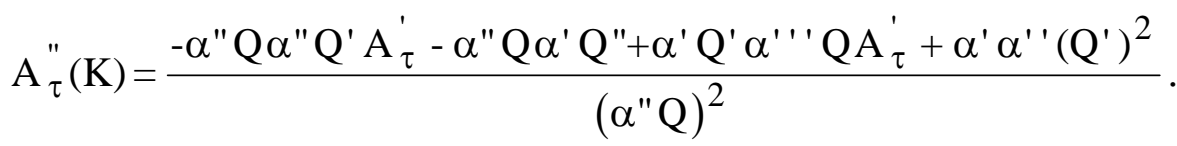

By substituting (16) for $A_{\tau}^{\prime}$ we obtain

$$
\mathrm{A}_{\tau}^{\prime \prime}(\mathrm{K})=\frac{1}{\left(\alpha^{\prime \prime}\right)^{3} \mathrm{Q}^{2}}\left[\alpha^{\prime}\left(\alpha^{\prime \prime}\right)^{2}\left\{\left(\mathrm{Q}^{\prime}\right)^{2}-\mathrm{QQ} "\right\}-\alpha^{\prime}\left(\mathrm{Q}^{\prime}\right)^{2}\left\{\alpha^{\prime} \alpha^{\prime \prime \prime}-\left(\alpha^{\prime \prime}\right)^{2}\right\}\right] .
$$


Unfortunately, the sign of $A_{\tau}^{\prime \prime}(K)$ is ambiguous because the sign of $\alpha^{\prime \prime \prime}$ is, in general, unknown.

However, in the special case of an abatement effectiveness function which is exponential, i.e.

$$
\alpha(\mathrm{A})=\alpha(0) \mathrm{e}^{-\mathrm{bA}}, \quad \mathrm{b} \ldots \text { constant }
$$

then $\left(\alpha^{\prime \prime}\right)^{2}-\alpha^{\prime} \alpha^{\prime \prime \prime}=0$ and $\mathrm{A}_{\tau}^{\prime \prime}(\mathrm{K})<0$.

Summing up the results of Step 1 we can formulate

\section{Proposition 1:}

For a given tax rate, $\tau$, the optimal level of abatement only depends on the stock of capital. If $\mathrm{K}<\tilde{\mathrm{K}}$ with $\tilde{\mathrm{K}}$ from (15), then the firm will not carry out any cleaning activities. For $\mathrm{K}>\tilde{\mathrm{K}}$ abatement is positive and increases with $\mathrm{K}$. In the special case of (18), abatement is a concave function of $K$.

\subsection{The Step 2 Problem}

With $\mathrm{A}(\mathrm{K})$ computed in Step 1 solve the following (Step 2) control problem:

$$
\begin{aligned}
& \max _{\mathrm{I}} \int_{0}^{\infty} \mathrm{e}^{-\mathrm{rt}}\{\mathrm{pQ}(\mathrm{K})-\mathrm{vA}(\mathrm{K})-\mathrm{C}(\mathrm{I})-\tau \alpha(\mathrm{A}(\mathrm{K})) \mathrm{Q}(\mathrm{K})\} \mathrm{dt} \\
& \text { s.t. } \quad \dot{\mathrm{K}}=\mathrm{I}-\mathrm{aK}, \quad \mathrm{K}(0)=\mathrm{K}_{0} .
\end{aligned}
$$

This leads to the following Hamiltonian

$$
H=p Q(K)-v A(K)-C(I)-\tau \alpha(A(K)) Q(K)+\lambda(I-a K),
$$

and the necessary optimality conditions are:

$$
\begin{aligned}
& I=\underset{I}{\arg \max } H \quad \text { i.e. } \quad \lambda=C^{\prime}(I) \\
& \dot{\lambda}=\mathrm{r} \lambda-\mathrm{H}_{\mathrm{K}} \\
& =(\mathrm{r}+\mathrm{a}) \lambda-\mathrm{pQ}^{\prime}(\mathrm{K})+\mathrm{vA}^{\prime}(\mathrm{K})+\tau \alpha^{\prime}(\mathrm{A}(\mathrm{K})) \mathrm{A}^{\prime}(\mathrm{K}) \mathrm{Q}(\mathrm{K})+\tau \alpha(\mathrm{A}(\mathrm{K})) \mathrm{Q}^{\prime}(\mathrm{K})
\end{aligned}
$$

where $\lambda$ is the current value costate variable of capital stock. The latter equation can be simplified to

$$
\begin{gathered}
\dot{\lambda}=(\mathrm{r}+\mathrm{a}) \lambda-(\mathrm{p}-\tau \alpha(\mathrm{A}(\mathrm{K}))) \mathrm{Q}^{\prime}(\mathrm{K})+\mathrm{A}^{\prime}(\mathrm{K})\left(\mathrm{v}+\tau \alpha^{\prime}(\mathrm{A}(\mathrm{K})) \mathrm{Q}(\mathrm{K})\right)= \\
(\mathrm{r}+\mathrm{a}) \lambda-(\mathrm{p}-\tau \alpha(\mathrm{A}(\mathrm{K}))) \mathrm{Q}^{\prime}(\mathrm{K}),
\end{gathered}
$$


where the latter equality follows from (13) and (14). In particular, (14) implies that $\mathrm{H}$ is differentiable w.r.t. $\mathrm{K}$ even at the point $\tilde{\mathrm{K}}$, where the function $\mathrm{A}(\mathrm{K})$ has a kink.

For $\mathrm{t} \rightarrow \infty$ we require the limiting transversality condition to hold:

$$
\lim _{\mathrm{t} \rightarrow \infty} \mathrm{e}^{-\mathrm{rt}} \lambda(\mathrm{t})=0 .
$$

Unfortunately, the usual sufficiency conditions (using concavity) are not satisfied. Also, it is difficult to verify any of the existing results on the limiting transversality condition to be a necessary condition. Nevertheless for reasons of economic interpretation it is not unreasonable to assume that only those solutions make sense whose shadow price $\lambda$ remains bounded or does not diverge at a rate larger than the discount rate.

\subsection{Qualitative Analysis in the Phase Plane}

In order to perform a phase plane analysis in the (K,I)-plane we first observe that the $\dot{K}=0$ isocline is the straight line $\mathrm{I}=\mathrm{aK}$. Next, we have to derive a differential equation for I from the adjoint equation (23). This is done by differentiating (22) w.r.t. time $t$ and subsequent elimination of the costate $\lambda$. This yields 3 ):

$$
\begin{aligned}
& \dot{\mathrm{I}}=\frac{1}{\mathrm{C}^{\prime \prime}(\mathrm{I})}\left[(\mathrm{r}+\mathrm{a}) \mathrm{C}^{\prime}(\mathrm{I})-\{\mathrm{p}-\tau \alpha(0)\} \mathrm{Q}^{\prime}(\mathrm{K})\right] \text { for } \mathrm{K} \leq \tilde{\mathrm{K}}, \\
& \dot{\mathrm{I}}=\frac{1}{\mathrm{C}^{\prime \prime}(\mathrm{I})}\left[(\mathrm{r}+\mathrm{a}) \mathrm{C}^{\prime}(\mathrm{I})-\left\{\mathrm{p}-\tau \alpha\left(\mathrm{A}_{\tau}(\mathrm{K})\right)\right\} \mathrm{Q}^{\prime}(\mathrm{K})\right] \text { for } \mathrm{K}>\tilde{\mathrm{K}} .
\end{aligned}
$$

With these, we can compute the slope of the $\dot{I}=0$ isocline. It is convenient to treat the two cases separately. First, we consider the case of a small capital stock where zero abatement is optimal, i.e., $\mathrm{K} \leq \tilde{\mathrm{K}}$. In this case we obtain from $(\mathrm{r}+\mathrm{a}) \mathrm{C}^{\prime}(\mathrm{I})-(\mathrm{p}-\tau \alpha(0)) \mathrm{Q}^{\prime}(\mathrm{K})=0$ that

$$
\left.\frac{\mathrm{dI}}{\mathrm{dK}}\right|_{\mathrm{I}=0}=\frac{(\mathrm{p}-\tau \alpha(0)) \mathrm{Q}^{\prime \prime}(\mathrm{K})}{(\mathrm{r}+\mathrm{a}) \mathrm{C}^{\prime \prime}(\mathrm{I})}<0
$$

provided that $p-\tau \alpha(0)>0$, which is assumed in (6).

Next, we consider the case of a larger capital stock where positive abatement is optimal, i.e., $\mathrm{K}>\tilde{\mathrm{K}}$. In this case we obtain from $(\mathrm{r}+\mathrm{a}) \mathrm{C}^{\prime}(\mathrm{I})-\left\{\mathrm{p}-\tau \alpha\left(\mathrm{A}_{\tau}(\mathrm{K})\right)\right\} \mathrm{Q}^{\prime}(\mathrm{K})=0$ that

3) By comparing (24) and (25) we see that for $\mathrm{K}>\tilde{\mathrm{K}}$ the $\dot{I}=0$ isocline lies above the corresponding $\dot{I}=0$ isocline for A $=0$ as given by (24). Also, because of (13) and (14), there is no jump at $\mathrm{K}=\tilde{\mathrm{K}}$. Finally, it is clear that the $\dot{I}=0$ isocline always lies below the corresponding $\dot{I}=0$ isocline for for the unregulated case, i.e., for $\tau=0$. 


$$
\left.\frac{\mathrm{dI}}{\mathrm{dK}}\right|_{\mathrm{I}=0}=\frac{\mathrm{Q}^{\prime \prime}\left(\mathrm{p}-\tau \alpha\left(\mathrm{A}_{\tau}\right)\right)-\mathrm{Q}^{\prime} \tau \alpha^{\prime}\left(\mathrm{A}_{\tau}\right) \mathrm{A}_{\tau}^{\prime}}{(\mathrm{r}+\mathrm{a}) \mathrm{C}^{\prime \prime}}=\frac{\mathrm{pQ} \mathrm{Q}^{\prime \prime} \alpha^{\prime \prime} \mathrm{Q}-\tau \alpha \alpha^{\prime \prime} \mathrm{QQ} \mathrm{Q}^{\prime \prime}+\tau\left(\alpha^{\prime}\right)^{2}\left(\mathrm{Q}^{\prime}\right)^{2}}{(\mathrm{r}+\mathrm{a}) \mathrm{C}^{\prime \prime} \alpha^{\prime \prime} \mathrm{Q}}
$$

The sign of this expression is ambiguous. From equations (26) and (27) we obtain that the $\dot{\mathrm{I}}=0$ isocline has a kink at $\tilde{\mathrm{K}}$, where the right-hand side derivative exceeds the left-hand side derivative.

Let us now consider the steady state $\left(\mathrm{K}^{*}, \mathrm{I}^{*}\right)$ which is defined by

$$
\mathrm{I}^{*}=\mathrm{aK}^{*}, \quad\{\mathrm{p}-\tau \alpha(0)\} \mathrm{Q}^{\prime}\left(\mathrm{K}^{*}\right)=(\mathrm{r}+\mathrm{a}) \mathrm{C}^{\prime}\left(\mathrm{I}^{*}\right)
$$

if $\mathrm{K}^{*}<\tilde{\mathrm{K}}$. Note that, by (28), a necessary condition for an equilibrium to exist is that $\mathrm{p}-\tau \alpha(0)>0$, which we have assumed in (6). The second equation in (28) says that in the equilibrium marginal revenue, net from paying emissions tax, equals marginal investment costs. We also see that the equilibrium capital stock decreases when the emissions tax rate increases.

The determinant of the Jacobian of the dynamical system (20) and (24) evaluated at the equilibrium can easily be computed (cf. Feichtinger and Hartl (1986)):

$$
\text { det } \mathrm{J}=\frac{1}{\mathrm{C}^{\prime \prime}}\left\{-\mathrm{a}(\mathrm{r}+\mathrm{a}) \mathrm{C}^{\prime \prime}+[\mathrm{p}-\tau \alpha(0)] \mathrm{Q}^{\prime \prime}\right\}<0,
$$

which means that:

\section{Proposition 2:}

If an equilibrium with $\mathrm{K}^{*}<\tilde{\mathrm{K}}$ exists, then it is a saddle point.

On the other hand, for $\mathrm{K}^{*}>\tilde{\mathrm{K}}$, the steady state is defined by

$$
\mathrm{I}^{*}=\mathrm{aK}^{*}, \quad(\mathrm{r}+\mathrm{a}) \mathrm{C}^{\prime}\left(\mathrm{I}^{*}\right)=\left\{\mathrm{p}-\tau \alpha\left(\mathrm{A}_{\tau}\left(\mathrm{K}^{*}\right)\right)\right\} \mathrm{Q}^{\prime}\left(\mathrm{K}^{*}\right) .
$$

Also here net marginal revenue equals marginal costs. The difference with (28) is that here the firm spends money on abatement in order to reduce the emissions tax payment. As we already know, the level of abatement expenditures is fixed such that the price of one unit of abatement, $\mathrm{v}$, equals the tax reduction due to one unit of abatement, $-\tau \alpha^{\prime} \mathrm{Q}$; cf. (14).

Contrary to the equilibrium represented by (28) where abatement expenditures are zero, here it is not so clear what happens to the equilibrium capital stock when the emissions tax rate increases. To see this let us partially differentiate (30) w.r.t. $\mathrm{K}^{*}$ and tau to obtain:

$$
\frac{\mathrm{dK}^{*}}{\mathrm{~d} \tau}=\frac{\mathrm{Q}^{\prime}\left[\alpha \alpha^{\prime \prime}-\alpha^{\prime 2}\right]}{\alpha^{\prime \prime}\left[(\mathrm{p}-\tau \alpha) \mathrm{Q}^{\prime \prime}-\mathrm{a}(\mathrm{r}+\mathrm{a}) \mathrm{C}^{\prime \prime}-\tau \alpha^{\prime} \mathrm{Q}^{\prime} \mathrm{A}_{\tau}^{\prime}\right]}
$$


The first term of the numerator is positive and the second term is negative. In the denominator the first two terms are negative while the last one is positive. Hence, the sign of $\mathrm{dK} * / \mathrm{d} \tau$ is not clear. The economic explanation of this ambiguity is that there are two forces working at the same time. The first one is what in Carraro and Soubeyran (1995) is called the marginal tax effect, by which is meant the additional cost introduced by the emissions tax increase. Due to this effect the equilibrium capital stock decreases.

Carraro and Soubeyran (1995) denote the second effect as the marginal abatement effect. Increased emissions taxes will stimulate abatement expenses according to (14). This leads to a reduction of the emissions to capital ratio, which in turn has a negative effect on the emissions taxes to be paid by the firm. Due to this effect the equilibrium capital stock increases. The same contrary effects on the capital stock can be found in Katsoulacos and Xepapadeas (1995).

Consider once again the equilibrium expressed by (28). here abatement expenditures are zero implying that the marginal abatement effect is absent. Therefore, only the marginal tax effect works here, so that it is understandable that equilibrium capital stock decreases when the tax rate increases.

Now the dynamic system in the equilibrium (30) consists of (20) and (25), implying that the determinant of the Jacobian evaluated at the steady state equals

$$
\begin{aligned}
& \operatorname{det} J=\frac{1}{C^{\prime \prime}}\left\{-a(r+a) C^{\prime \prime}+[p-\tau \alpha] Q^{\prime \prime}-\tau \alpha^{\prime} A_{\tau}^{\prime} Q^{\prime}\right\} \\
& =\frac{1}{C^{\prime \prime}}\left\{-a(r+a) C^{\prime \prime}+[p-\tau \alpha] Q^{\prime \prime}+\frac{\tau\left(\alpha^{\prime} Q^{\prime}\right)^{2}}{\alpha^{\prime \prime} Q}\right\}=(r+a)\left(-a+\left.\frac{d I}{d K}\right|_{\dot{I}=0}\right) .
\end{aligned}
$$

Since a is the slope of the $\dot{K}=0$ isocline and det $\mathrm{J}$ is negative in case of a saddle point, this means that

\section{Proposition 3:}

If $\mathrm{K}^{*}>\tilde{\mathrm{K}}$ then the equilibrium $\left(\mathrm{K}^{*}, \mathrm{I}^{*}\right)$ is

- a saddle point, if the $\dot{I}=0$ isocline hits the $\dot{K}=0$ isocline from above

- $\quad$ unstable, if the $\dot{I}=0$ isocline hits the $\dot{K}=0$ isocline from below.

It is convenient to consider different cases: one where the $\dot{I}=0$ isocline is always decreasing and the other where it is not. From (27) we obtain that the $\dot{I}=0$ isocline is decreasing for a certain value of $\mathrm{K}>\widetilde{\mathrm{K}}$, if:

$$
\tau<\frac{p Q^{\prime \prime} \alpha^{\prime \prime} Q}{\alpha \alpha^{\prime \prime} Q^{\prime \prime}-\left(\alpha^{\prime} Q^{\prime}\right)^{2}} .
$$


Thus, we obtain that a globally decreasing $\dot{I}=0$ isocline occurs if $\tau<\tau^{*}$, where $\tau^{*}$ is given by:

$$
\tau^{*}=\min _{\mathrm{K}}\left\{\frac{\mathrm{pQ} \mathrm{Q}^{\prime \prime} \mathrm{Q}}{\alpha \alpha^{\prime \prime} \mathrm{QQ}^{\prime \prime}-\left(\alpha^{\prime} \mathrm{Q}^{\prime}\right)^{2}} \mid \mathrm{A}=\mathrm{A}_{\tau}(\mathrm{K}), \mathrm{K}>\tilde{\mathrm{K}}\right\} .
$$

The fact that the $\dot{I}=0$ isocline can have a positive slope for large $\tau$ can be explained by noting that for large $\tau$ the emissions tax per unit of output, $\tau \alpha\left(\mathrm{A}_{\tau}(\mathrm{K})\right)$, decreases considerably when $\mathrm{K}$ increases (here we must remember that $\alpha^{\prime}<0$ and $\mathrm{A}_{\tau}^{\prime}>0$ ). In (25) this decrease can cancel the reduction of marginal revenue $Q^{\prime}(K)$ due to increasing $K$ so that investments increase with capital stock on the $\dot{I}=0$ isocline.

It is now convenient to consider the two cases of mild environmental taxation, $\tau<\tau^{*}$ and strict taxation, $\tau>\tau^{*}$, separately. This will be done in the next two sections.

\section{The Case of Mild Environmental Taxation}

Let us first consider the case $\tau<\tau^{*}$ where the $\dot{I}=0$ isocline is globally decreasing and there exists a single equilibrium $K^{*}$. This situation is depicted in Figure 1

Figure 1 here

If the equilibrium $\mathrm{K}^{*}$ is less than $\tilde{\mathrm{K}}$, then its value is determined by (28). According to Proposition 2 this equilibrium is a saddle point. If $K^{*}$ exceeds $\tilde{K}$, then (30) holds. Since here the $\dot{I}=0$ isocline decreases everywhere and the $\dot{K}=0$ isocline always increases, the $\dot{\mathrm{I}}=0$ isocline hits the $\dot{\mathrm{K}}=0$ isocline from above in the equilibrium. Now, from Proposition 3 we obtain that this equilibrium is also a saddle point.

So far we only talked about the equilibrium and we did not say anything about what happens on the path towards the equilibrium. It would be interesting to know how the investment rate is determined on this path. After solving the differential equation (23), substituting (22) into this relation, and using (30), or (28) when $\mathrm{K}^{*}<\tilde{\mathrm{K}}$, as a fixed point, we obtain the following condition for the investment rate which holds for every $\mathrm{t}$ :

$$
\int_{\mathrm{t}}^{\infty} \mathrm{e}^{-(\mathrm{r}+\mathrm{a})(\mathrm{s}-\mathrm{t})}\{\mathrm{p}-\tau \alpha(\mathrm{A}(\mathrm{K}(\mathrm{s})))\} \mathrm{Q}^{\prime}(\mathrm{K}(\mathrm{s})) \mathrm{ds}-\mathrm{C}^{\prime}(\mathrm{I}(\mathrm{t}))=0
$$

where the left-hand side is the net present value of marginal investment. For an interpretation consider the acquisition of an extra unit of capital at time $t$. The firm incurs an extra expense at time $t$ in amount of $C^{\prime}$. On the other hand, the marginal unit of capital generates - as of time $t$ - a stream of revenue $p Q^{\prime}$ and it also generates a stream of 
emissions tax payments $\left.{ }^{4}\right) \tau \alpha Q^{\prime}$. Both streams are corrected for depreciation by multiplication by $\mathrm{e}^{-\mathrm{a}(\mathrm{s}-\mathrm{t})}$ and are discounted to time $\mathrm{t}$ by multiplication by $\mathrm{e}^{-\mathrm{r}(\mathrm{s}-\mathrm{t})}$. Therefore, condition (33) states that the net present value of marginal investment equals zero, so that the fundamental economic principle of balancing marginal revenue with marginal expenses applies.

From (28) and (30) we learn that an emissions tax has a negative effect on the final steady state capital stock (see also Figure 1). Moreover, due to the following proposition, whose proof is based on equation (33), we know that an emissions tax causes the capital stock to be lower on the whole trajectory (except at $t=0$ where $K(0)=K_{0}$ ) as well.

\section{Proposition 4:}

Define $\mathrm{K}_{\mathrm{u}}(\mathrm{t})$ to be the optimal level of the capital stock in the unregulated case, i.e. for $\tau=0$. Then it holds that

$$
\mathrm{K}(\mathrm{t})<\mathrm{K}_{\mathrm{u}}(\mathrm{t}) \text { for all } \mathrm{t} \in(0, \infty)
$$

Proof: See the Appendix.

Furthermore, differentiating the marginal emissions tax payments $\tau \alpha Q^{\prime}$ (see also footnote 4) totally w.r.t. K shows that they decrease with $K$, so that these costs have a more significant effect on investments when the firm is small.

\section{The Case of Strict Environmental Taxation}

Let us now turn to the case $\tau>\tau^{*}$ where the $\dot{I}=0$ isocline is not globally decreasing. Now, multiple equilibria can occur, since the two isoclines can have more than one point of intersection. We illustrate this situation in the case of the abatement function (18), and the following production function:

$$
\mathrm{Q}(\mathrm{K})=\mathrm{K}^{\mathrm{C}}, 0<\mathrm{C}<1
$$

In this case, $\alpha^{\prime 2}-\alpha \alpha^{\prime \prime}=0, \mathrm{Q}^{\prime 2}=\mathrm{c}^{2} \mathrm{~K}^{2 \mathrm{c}-2}, \mathrm{QQ}^{\prime \prime}=\mathrm{c}(\mathrm{c}-1) \mathrm{K}^{2 \mathrm{c}-2}$ and $\mathrm{t}$ herefore $\mathrm{Q}^{\prime 2}-\mathrm{QQ}^{\prime \prime}=\mathrm{cK}^{2 \mathrm{c}-2}$.

Hence, the numerator of the r.h.s. of (27) becomes:

$$
\alpha^{\prime \prime} K^{2 c-2} c[\tau \alpha+p(c-1)]
$$

so that $\tau^{*}$ from (32) becomes:

4) Notice that if $K$ increases then total emissions tax payments $\tau \alpha Q$ change with $\tau \alpha \mathrm{Q}^{\prime}+\tau \alpha^{\prime} \mathrm{QA}^{\prime}$. However $\tau \alpha^{\prime} \mathrm{QA}^{\prime}$ and the expected abatement expenditures $\mathrm{vA}^{\prime}$ cancel each other, as can be seen from (14). 


$$
\tau^{*}=\frac{p(1-c)}{\alpha(0)}
$$

Since $A(\tilde{K})=A_{\tau}(\tilde{K})=0, A(K)$ is increasing with $K$ for $K>\tilde{K}$, and therefore $\alpha(A(K))$ is decreasing with $\mathrm{K}$ for $\mathrm{K}>\tilde{\mathrm{K}}$, we can conclude:

\section{Proposition 5}

In case of (18) and (34), the $\dot{I}=0$ isocline for $\mathrm{K}>\tilde{\mathrm{K}}$ and $\tau>\tau^{*}$ changes its monotonicity property once. There exists a capital stock $\hat{\mathrm{K}}(>\tilde{\mathrm{K}})$, such that it is increasing in a first interval $[\tilde{\mathrm{K}}, \hat{\mathrm{K}}]$ and decreasing for $\mathrm{K}>\hat{\mathrm{K}}$.

A typical phase diagram is sketched in Figure 2. We note that the long run optimal capital stock levels still satisfy equation (28) for $\mathrm{K}^{*}<\tilde{\mathrm{K}}$ and equation (30) for $\mathrm{K}^{*}>\widetilde{\mathrm{K}}$. Also, the firm's investment behavior can still be explained by the net present value relation (33).

\section{Figure 2 here}

The system has two equilibria, $\mathrm{K}_{\mathrm{H}}$ and also $\mathrm{K}_{\mathrm{G}}$, which are saddle-points. Furthermore, there exists a third equilibrium $K_{N}$ for $K>\tilde{K}$ where the $\dot{I}=0$ isocline hits the $\dot{K}=0$ isocline from below, which is therefore unstable (cf. Proposition 3).

This unstable equilibrium can be a node or a focus (see, e.g., Feichtinger and Hartl, 1986, p. 105). If it is a focus, then we know from the literature (e.g. Skiba (1978) or Dechert (1984)) that there exists an interval of K-values that contains the unstable equilibrium, and on which two candidate trajectories occur. One trajectory goes to the right and ends in $\mathrm{K}_{\mathrm{G}^{\prime}}$ and the other one goes to the left and approaches $\mathrm{K}_{\mathrm{H}}$. From Dechert (1984) we know that a so called Skiba-point, $\mathrm{K}_{\mathrm{s}}$ say, can be identified such that for "large“ initial capital stocks, $\mathrm{K}>\mathrm{K}_{\mathrm{S}}$, the trajectory to the right is better, and for small initial capital stocks, $\mathrm{K}<\mathrm{K}_{\mathrm{s}}$, the trajectory to the left generates a higher value of the objective ${ }^{5)}$. These equilibria $\mathrm{K}_{\mathrm{G}}$ and $\mathrm{K}_{\mathrm{H}}$ are called history dependent, since it depends on the history, i.e. on $\mathrm{K}(0)$, which one is approached. This situation is sketched in Figure 2.

It can also happen that the unstable equilibrium is a node. This means that we still have history dependent equilibria and the critical point (where to go to left or right) is simply the unstable node $\mathrm{K}_{\mathrm{N}}$. Since this situation is simpler than the case of a focus, we refrain from drawing a picture here.

5) The reason is that for fixed $K$, the (maximized) Hamiltonian and therefore also the value function assumes its minimum value along the $\dot{K}=0$ isocline so that on the left boundary of the overlapping interval the left trajectory is better, and on the right boundary the right trajectory is better; see also Feichtinger and Hartl (1986, p. 117). The existence of a Skiba point in between follows from continuity. 
As stated before, multiple equilibria only occur for a sufficiently large tax rate, implying that at the same time equilibria with different stocks of capital goods are optimal. This can be explained as follows. First, notice that abatement expenditures increase with capital stock, and this leads to a reduction of the emissions to output ratio. Hence, if capital stock is large the firm pays less emissions tax per unit of output, and this scale effect is particularly significant when the tax rate is large. On the other hand we have the usual effect of decreasing marginal revenue when capital stock rises. We conclude that a trade off is at hand here in the sense that an equilibrium with a large stock of capital goods has the advantage of relatively low emissions tax payments but suffers from low marginal revenues, whereas an equilibrium with a low stock of capital goods enjoys high marginal revenues but also has high marginal emissions tax payments.

From Figure 2 we infer that we have history dependent equilibria in the sense that when $\mathrm{K}$ is below $\mathrm{K}_{\mathrm{S}}$ (or $\mathrm{K}_{\mathrm{N}}$ in case of an unstable node) it is optimal to approach the low capital stock equilibrium $\mathrm{K}_{\mathrm{H}}$ rather than converging to $\mathrm{K}_{\mathrm{G}}$ and vice versa. From an economic point of view this can be explained by the fact that for low values of capital stock the emissions tax per unit of output is large. This implies that growing is less profitable for low values of capital stock, which makes it understandable that the small equilibrium $\mathrm{K}_{\mathrm{H}}$ is approached when the initial stock of capital goods is such that $K(0)<K_{S}$.

We conclude that, in general, the firm would converge to the large capital stock equilibrium $\mathrm{K}_{\mathrm{G}}$, if growing is sufficiently profitable at all stages of the growth process. If a government likes to pursue growth it can make growing more profitable by reducing the emissions tax or distributing an investment grant. In this way the government tempts the firm to approach $\mathrm{K}_{\mathrm{G}}$ rather than the small equilibrium $\mathrm{K}_{\mathrm{H}}$. Below we show this mathematically.

\subsection{An Extension Incorporating an Investment Grant}

Let us assume that the government wants to protect the environment so that it chooses for distributing the investment grant instead of an emissions tax reduction. If $\mathrm{g}$ is the investment grant, the firm's objective becomes

$$
\max _{\mathrm{I}, \mathrm{A}} \int_{0}^{\infty} \mathrm{e}^{-\mathrm{rt}}[\mathrm{pQ}(\mathrm{K})-\mathrm{vA}-\mathrm{C}(\mathrm{I})-\tau \alpha(\mathrm{A}) \mathrm{Q}(\mathrm{K})+\mathrm{gI}] \mathrm{dt} .
$$

This leads to the following expressions for I :

$$
\begin{aligned}
& \dot{\mathrm{I}}=\frac{1}{\mathrm{C}^{\prime \prime}(\mathrm{I})}\left[(\mathrm{r}+\mathrm{a})\left(\mathrm{C}^{\prime}(\mathrm{I})-\mathrm{g}\right)-(\mathrm{p}-\tau \alpha(0)) \mathrm{Q}^{\prime}(\mathrm{K})\right] \text { for } \mathrm{K} \leq \tilde{\mathrm{K}}, \\
& \dot{\mathrm{I}}=\frac{1}{\mathrm{C}^{\prime \prime}(\mathrm{I})}\left[(\mathrm{r}+\mathrm{a})\left(\mathrm{C}^{\prime}(\mathrm{I})-\mathrm{g}\right)-\left(\mathrm{p}-\tau \alpha\left(\mathrm{A}_{\tau}(\mathrm{K})\right)\right) \mathrm{Q}^{\prime}(\mathrm{K})\right] \text { for } \mathrm{K}>\tilde{\mathrm{K}} .
\end{aligned}
$$


Comparing these equations with (24) - (25) we conclude that the $\dot{I}=0$ isocline shifts upwards in the (K, I)-plane. If this upward shift is large enough, we infer from Figure 2 that the two equilibria $\mathrm{K}_{\mathrm{H}}$ and $\mathrm{K}_{\mathrm{N}}$ are eliminated. This implies that the firm then automatically converges to the large capital stock equilibrium $\mathrm{K}_{\mathrm{G}}$.

For this upward shift to be large enough it must hold that at $\tilde{K}$ the $\dot{I}=0$ isocline lies above the $\dot{\mathrm{K}}=0$ isocline. This is the case when the investment grant satisfies the following inequality:

$$
\mathrm{g}>\mathrm{C}^{\prime}(\mathrm{a} \tilde{\mathrm{K}})-(\mathrm{p}-\tau \alpha(0)) \mathrm{Q}^{\prime}(\tilde{\mathrm{K}}) /(\mathrm{r}+\mathrm{a}) .
$$

We see that when the emissions tax rate increases, also the investment grant has to increase in order to be sure that the firm will choose for the equilibrium $\mathrm{K}_{\mathrm{G}}$.

Of course, on the basis of this analysis we cannot conclude whether it pays for the government to distribute such a grant to the firm. To answer this question requires another model with the government as decision maker. Here we just focus on the optimal response of a firm to an exogenously given government policy.

\section{A Comparison with a Model with Standards}

In a previous paper, Hartl and Kort (1994), we have investigated a related model with pollution standards rather than a pollution tax rate:

$$
\begin{array}{ll}
\max _{\mathrm{I}, \mathrm{A}} \int_{0}^{\infty} \mathrm{e}^{-\mathrm{rt}}\{\mathrm{pQ}(\mathrm{K})-\mathrm{vA}-\mathrm{C}(\mathrm{I})\} \mathrm{dt} \\
\text { s.t. } \quad \dot{\mathrm{K}}=\mathrm{I}-\mathrm{aK}, \quad \mathrm{K}(0)=\mathrm{K}_{0} \\
\\
\mathrm{~A} \geq 0 \\
& \alpha(\mathrm{A}) \mathrm{Q}(\mathrm{K}) \leq \mathrm{Z} .
\end{array}
$$

In the standards case the firm never spends money on abatement as long as pollution remains below its fixed upper bound $Z$. Hence abatement is zero when capital stock is that low that the pollution constraint is not violated for $\mathrm{A}=0$. The reason is that it makes no sense to spend money on abatement when it is not necessary to reduce pollution. The resemblance with environmental regulation in the form of a tax is that also in this case abatement expenditures are zero when capital stock is low, but now the reason is that abatement does not lead to a severe reduction of pollution, and thus not to a severe reduction of the emissions tax, when $\mathrm{K}$ is low.

When $\mathrm{K}$ is larger, abatement is necessary to stay below the emission limit, and this abatement expenditure, denoted by $\mathrm{A}_{Z}(\mathrm{~K})$, depends on the capital stock $\mathrm{K}$ and the standard Z: 


$$
\alpha\left(\mathrm{A}_{\mathrm{Z}}(\mathrm{K})\right) \mathrm{Q}(\mathrm{K})=\mathrm{Z} .
$$

The implication for the equilibrium levels is that in the standards case no pollution costs occur when capital stock is that low that the standard is always satisfied, i.e. the equilibrium is given by

$$
(\mathrm{r}+\mathrm{a}) \mathrm{C}^{\prime}\left(\mathrm{aK}^{*}\right)=\mathrm{pQ}^{\prime}\left(\mathrm{K}^{*}\right) .
$$

In the tax case, however, pollution tax has to be paid even when capital stock is low. Consequently, the equilibrium level is always affected by pollution costs, as can be seen from (28).

Due to the above we can conclude that a small firm will prefer environmental regulation in the form of a pollution standard rather than a tax.

If in the standards case the capital stock is that large that the firm needs to abate in order to satisfy the emissions constraint, the equilibrium is given by

$$
(\mathrm{r}+\mathrm{a}) \mathrm{C}^{\prime}\left(\mathrm{aK}^{*}\right)+\mathrm{vA}_{\mathrm{Z}}^{\prime}\left(\mathrm{K}^{*}\right)=\mathrm{pQ}^{\prime}\left(\mathrm{K}^{*}\right) .
$$

Here $\mathrm{vA}_{Z}^{\prime}$ equals the additional abatement expenses necessary to keep on satisfying the standard when capital stock increases marginally. Mathematically it holds that (see Hartl and Kort (1994))

$$
\mathrm{A}_{Z}^{\prime}(\mathrm{K})=-\mathrm{Q}^{\prime}(\mathrm{K}) \alpha\left(\mathrm{A}_{\mathrm{Z}}\right) / \mathrm{Q}(\mathrm{K}) \alpha^{\prime}\left(\mathrm{A}_{\mathrm{Z}}\right) .
$$

In the tax case the equilibrium level for large capital stock levels is determined by (30). Combining (30) and (40) leads to the conclusion that the equilibrium levels in both cases are the same when

$$
\mathrm{vA}_{\mathrm{Z}}^{\prime}\left(\mathrm{K}^{*}\right)=\tau \alpha\left(\mathrm{A}_{\tau}\left(\mathrm{K}^{*}\right)\right) \mathrm{Q}^{\prime}\left(\mathrm{K}^{*}\right) .
$$

From (14), (41) and (42) we obtain

$$
\alpha^{\prime}\left(\mathrm{A}_{\tau}\right) / \alpha\left(\mathrm{A}_{\tau}\right)=\alpha^{\prime}\left(\mathrm{A}_{\mathrm{Z}}\right) / \alpha\left(\mathrm{A}_{\mathrm{Z}}\right)
$$

which holds, for instance, in case that the emissions to output ratio is an exponential function of abatement; see e.g. (18).

Now let us compare the optimal investment programs for both cases. If the government regulates emissions through a standard and the firm is that small that the standard is never violated without needing to use abatement, then the firm's investment policy satisfies 
$\int_{\mathrm{t}}^{\infty} \mathrm{pQ}^{\prime}(\mathrm{K}(\mathrm{s})) \mathrm{e}^{-(\mathrm{a}+\mathrm{r})(\mathrm{s}-\mathrm{t})} \mathrm{ds}-\mathrm{C}^{\prime}(\mathrm{I}(\mathrm{t}))=0$.

As concluded before, in the standards case environmental regulation does not affect the firm's behaviour when the emissions constraint is not binding. This means that investments are the same as in the unregulated case. Due to Proposition 4 we conclude that for the whole planning period (except $t=0$ ) it holds that capital stock under standards regulation exceeds capital stock under tax regulation. Therefore, and also because here abatement expenditures are zero under the standard, emissions will be higher in the standard case.

Let us assume that the firm starts out with a low capital stock and that at a certain moment, say $t^{\prime}$ the standard becomes binding. Then the firm's investment rate satisfies the following net present value equation (see Hartl and Kort, 1994):

$$
\int_{t}^{\infty} p Q^{\prime}(K(s)) e^{-(a+r)(s-t)} d s-\int_{t^{\prime}}^{\infty} v A_{Z}^{\prime}(K(s)) e^{-(a+r)(s-t)} d s-C^{\prime}(I(t))=0
$$

We see that when it determines its investment rate, the firm already takes into account future abatement expenditures, which are necessary to satisfy the standard, even when the pollution constraint is not yet binding. Hence, here we have an exception to the rule that environmental regulation does not influence firm's behaviour when the standard is not binding.

If we compare (45) with (33) we see that when the standard is binding at the initial time, i.e. $\mathrm{t}^{\prime}=\mathrm{t}$ in (45), the investment rate is the same for both cases if

$$
\tau \alpha(\mathrm{A}(\mathrm{K}(\mathrm{t}))) \mathrm{Q}^{\prime}(\mathrm{K}(\mathrm{t}))=\mathrm{vA}_{\mathrm{Z}}^{\prime}(\mathrm{K}(\mathrm{t})) \text { for all } \mathrm{t} \in[0, \infty)
$$

From (14) and (41) we obtain that this condition is fulfilled in case that, for instance, $\mathrm{K}(0)>\tilde{\mathrm{K}}$ (see (13)) and when the abatement effectiveness function is given by (18).

If the initial capital stock level is low the standard is not binding at time zero. Then there exists an initial time period in which abatement expenditures do not occur. According to (45) this will have a positive effect on the investment rate during this initial time period. In the tax case the opposite takes place when the initial capital stock level is low. Then output will be that low that it is not worthwhile for the firm to reduce tax payments by decreasing the emissions to output ratio. Therefore, abatement expenditures will be zero so that the marginal pollution costs $\tau \alpha Q^{\prime}$ are large. According to (33), initial investments will be negatively influenced by this.

We conclude that, compared to the standards case, environmental regulation in the form of a tax will suppress growth especially during the initial phase of a growing firm. 


\section{Conclusions}

In this paper we have determined optimal firm behaviour under environmental regulation in the form of an emissions tax. The firm produces goods which can be sold on the market at a fixed price. The production process obeys decreasing returns to scale and generates emissions, which can be reduced by carrying out abatement expenditures. The abatement process is modelled such that a given abatement expenditure leads to more pollution reduction if pollution is large. This implies that there are increasing returns to scale with respect to pollution reduction.

It turns out that, depending on the level of the tax rate, two different solutions occur. If the tax rate is sufficiently low, it is optimal to approach a unique long run optimal level of capital in an asymptotic way. This level is determined by an equality between marginal revenue and the sum of marginal interest, depreciation and pollution costs. Along the whole trajectory the firm's investment level is fixed such that immediate expenses, necessary to acquire an additional unit of capital stock, balance the discounted future cash inflow stream, net from emissions tax, which is due to this extra unit of capital stock. In case of a high tax rate the effect of increasing returns to scale with respect to pollution reduction is that significant that multiple equilibria occur. The fact that more than one level of capital stock can be optimal in the long run, is caused by the trade off between decreasing returns to production and increasing returns to pollution reduction, i.e. if capital stock is low the firm has a high marginal revenue but also high emissions tax payments per unit of production, while the emissions tax per unit of production and marginal revenue are low in case of a large capital stock. These equilibria are history dependent, because it depends on the initial level of capital stock which of the equilibria is optimal in the long run.

If we take welfare aspects into consideration one can identify these equilibria as being "good" or "bad" for society. This gives an incentive for the government to tempt the firm to approach the "good" equilibrium, which can be done by applying policy tools like taxes and subsidies (cf. Matsuyama, 1991). We have demonstrated that this is indeed possible in our model.

After comparing the emissions tax case with a dynamic model of a firm facing an emissions standard (Hartl and Kort, 1994), we conclude that the main difference is that in the standards case environmental regulation does not have such a strong effect on the growth of the firm when the firm is small. Under an emissions tax, however, growth will be suppressed especially during the initial phase of a growing firm. 


\section{References}

Carraro, C., Soubeyran, A., 1995, R\&D cooperation, innovation spillovers and firm's location in a model of environmental policy, paper presented at EU network meeting on "Environmental Policy and Technological Innovation" in Venice, 11-5-1995.

Clarke, F.H., 1983, Optimization and Nonsmooth Analysis, Wiley-Interscience, New York.

Dasgupta, P., 1982, The Control of Resources, Basil Blackwell, Oxford.

Dechert, W.D., 1984, Has the Averch-Johnson effect been theoretically justified? Journal of Economic Dynamics and Control, 8, 1-17.

Feichtinger, G., Hartl, R.F., 1986, Optimale Kontrolle ökonomischer Prozesse: Anwendungen des Maximumprinzips in den Wirtschaftswissenschaften, deGruyter, Berlin.

Hartl, R.F., 1988, A dynamic activity analysis for a monopolistic firm, Optimal Control Applications and Methods, 9, 253-272.

Hartl, R.F., Kort, P.M., 1994, Capital Accumulation of a Firm facing Environmental Constraints, Working paper, Department of Economics and Management, University of Magdeburg

Jorgenson, D.W., Wilcoxen, P.J., 1990, Environmental regulation and U.S. economic growth, Rand Journal of Economics, 21, 314-340.

Katsoulacos, Y., Xepapadeas, A., 1995, Environmental R\&D, spillovers and optimal policy schemes under oligopoly, paper presented at EU network meeting on

"Environmental Policy and Technological Innovation" in Venice, 11-5-1995.

Kort, P.M., Loon, P.J.J.M. van, Luptacik, M., 1991, Optimal dynamic environmental policies of a profit maximizing firm, Journal of Economics, 54, 195-225.

Matsuyama, K., 1991, Increasing returns, industrialization, and indeterminacy of equilibrium, Quarterly Journal of Economics, 106, 617-650.

Pigou, A.C. (1920), The Economics of Welfare, Mac Millan, New York.

Ploeg, F. van der, Withagen, C., 1991, Pollution control and the Ramsey problem, Environmental and Resource Economics, 1, 215-236.

Skiba, A.K., 1978, Optimal growth with a convex-concave production function, Econometrica, 46, 527-539.

Xepapadeas, A.P., 1992, Environmental policy, adjustment costs, and behavior of the firm, Journal of Environmental Economics and Management, 23, 258-275. 


\section{Appendix: Proof of Proposition 4}

Due to (28) and (30) we know that for $\tau=0$ the equilibrium satisfies

$$
\mathrm{pQ}^{\prime}\left(\mathrm{K}_{\mathrm{u}}^{*}\right)=(\mathrm{r}+\mathrm{a}) \mathrm{C}^{\prime}\left(\mathrm{I}^{*}\right), \quad \mathrm{I}^{*}=\mathrm{aK}_{\mathrm{u}}^{*}
$$

From (33) we obtain that in the unregulated case the investment rate is given by

$$
\mathrm{C}^{\prime}(\mathrm{I}(\mathrm{t}))=\int_{\mathrm{t}}^{\infty} \mathrm{e}^{-(\mathrm{r}+\mathrm{a})(\mathrm{s}-\mathrm{t})} \mathrm{pQ} \mathrm{Q}^{\prime}\left(\mathrm{K}_{\mathrm{u}}(\mathrm{s})\right) \mathrm{ds}
$$

In Section 4 we already concluded that

$$
\mathrm{K}^{*}<\mathrm{K}_{\mathrm{u}}^{*} \text {. }
$$

Now, assume that Proposition 4 is not true. This implies that there exists a point of time, $t_{1}$, say, such that

$$
\mathrm{t}_{1}=\sup \left\{\mathrm{t} \mid \mathrm{K}(\mathrm{t})>\mathrm{K}_{\mathrm{u}}(\mathrm{t})\right\}
$$

Clearly, this implies $\mathrm{K}\left(\mathrm{t}_{1}\right)=\mathrm{K}_{\mathrm{u}}\left(\mathrm{t}_{1}\right)$. Figure 3 shows the development of $\mathrm{K}$ and $\mathrm{K}_{\mathrm{u}}$ when $\mathrm{t}_{1}$ exists.

\section{Figure 3 here}

At $t_{1}$ the capital stock increases more in the unregulated case which implies that

$$
\mathrm{I}_{\mathrm{u}}\left(\mathrm{t}_{1}\right) \geq \mathrm{I}\left(\mathrm{t}_{1}\right)
$$

which, due to (33) and (48), leads to

$$
\int_{\mathrm{t}_{1}}^{\infty} \mathrm{e}^{-(\mathrm{r}+\mathrm{a})(\mathrm{s}-\mathrm{t})} \mathrm{pQ}^{\prime}\left(\mathrm{K}_{\mathrm{u}}(\mathrm{s})\right) \mathrm{d} \mathrm{s} \geq \int_{\mathrm{t}_{1}}^{\infty} \mathrm{e}^{-(\mathrm{r}+\mathrm{a})(\mathrm{s}-\mathrm{t})}\{\mathrm{p}-\tau \alpha(\mathrm{A}(\mathrm{K}(\mathrm{s})))\} \mathrm{Q}^{\prime}(\mathrm{K}(\mathrm{s})) \mathrm{d} \mathrm{s} .
$$

From (50) it is clear that for $\mathrm{t} \in\left[\mathrm{t}_{1}-\varepsilon, \mathrm{t}_{1}\right)$ and small $\varepsilon>0$, it holds that $\mathrm{Q}^{\prime}\left(\mathrm{K}_{\mathrm{u}}\right)>\mathrm{Q}^{\prime}(\mathrm{K})$, which via (52) implies that for $\mathrm{t} \in\left[\mathrm{t}_{1}-\varepsilon, \mathrm{t}_{1}\right)$

$$
\int_{\mathrm{t}}^{\infty} \mathrm{e}^{-(\mathrm{r}+\mathrm{a})(\mathrm{s}-\mathrm{t})} \mathrm{pQ}^{\prime}\left(\mathrm{K}_{\mathrm{u}}(\mathrm{s})\right) \mathrm{ds}>\int_{\mathrm{t}}^{\infty} \mathrm{e}^{-(\mathrm{r}+\mathrm{a})(\mathrm{s}-\mathrm{t})}\{\mathrm{p}-\tau \alpha(\mathrm{A}(\mathrm{K}(\mathrm{s})))\} \mathrm{Q}^{\prime}(\mathrm{K}(\mathrm{s})) \mathrm{d} \mathrm{s} .
$$

From (33), (48) and (53) we conclude that $\mathrm{I}_{\mathrm{u}}(\mathrm{t})>\mathrm{I}(\mathrm{t})$ for $\mathrm{t} \in\left[\mathrm{t}_{1}-\varepsilon, \mathrm{t}_{1}\right)$ and small $\varepsilon>0$. Now we show that $K_{u}(t)<K(t), I_{u}(t)>I(t)$ and therefore (53) must hold for all $t \in\left[0, t_{1}\right)$ since otherwise there exists a $t_{2}<t_{1}$ such that $K_{u}\left(t_{2}\right)=K\left(t_{2}\right)$; see Figure 3. Now, because of $\mathrm{I}_{\mathrm{u}}(\mathrm{t})>\mathrm{I}(\mathrm{t})$ in $\left(\mathrm{t}_{2}, \mathrm{t}_{1}\right)$ and (8) this would imply $\mathrm{K}_{\mathrm{u}}\left(\mathrm{t}_{1}\right)>\mathrm{K}\left(\mathrm{t}_{1}\right)$ which is a contradiction to $\mathrm{K}_{\mathrm{u}}\left(\mathrm{t}_{1}\right)=\mathrm{K}\left(\mathrm{t}_{1}\right)$ in (50). Thus we have

$$
\mathrm{K}_{\mathrm{u}}(\mathrm{t})<\mathrm{K}(\mathrm{t}) \text { and } \mathrm{I}_{\mathrm{u}}(\mathrm{t})>\mathrm{I}(\mathrm{t}) \text { for } \mathrm{t} \in\left[0, \mathrm{t}_{1}\right)
$$

which is, however, contradictory to the fact that the initial capital stock level is fixed at $\mathrm{K}_{0}$, i.e. $K_{u}(0)=K(0)=K_{0}$. Therefore $t_{1}$ does not exist, implying that Proposition 4 holds. 


\section{Contents}

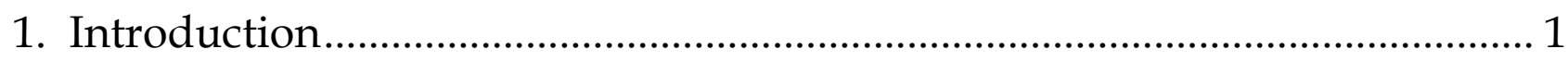

2. Model Formulation ................................................................................... 1

3. Mathematical Analysis and Economic Interpretations...................................... 3

3.1. The Step 1 Problem …………………………………................................................. 3

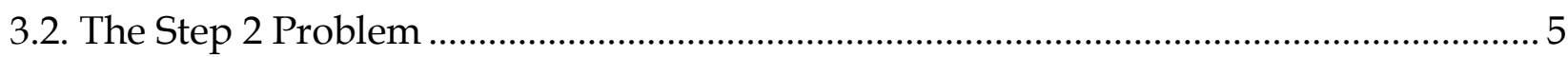

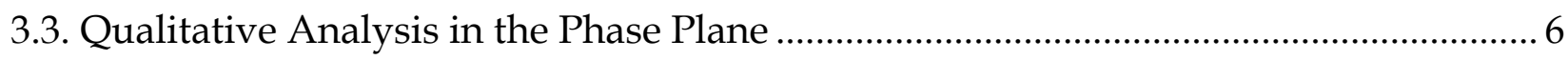

4. The Case of Mild Environmental Taxation............................................................ 9

5. The Case of Strict Environmental Taxation ................................................... 10

5.1. An Extension Incorporating an Investment Grant .......................................................... 12

6. A Comparison with a Model with Standards .................................................. 13

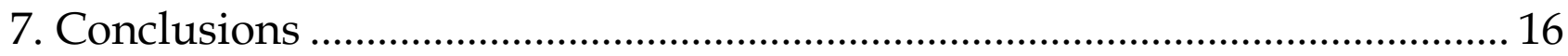

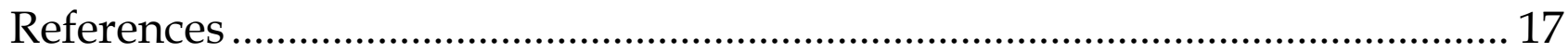

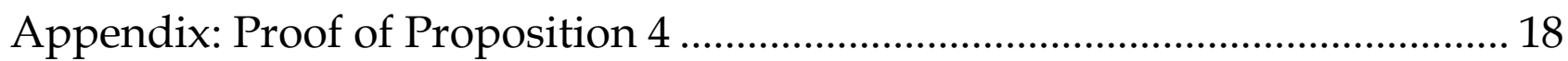




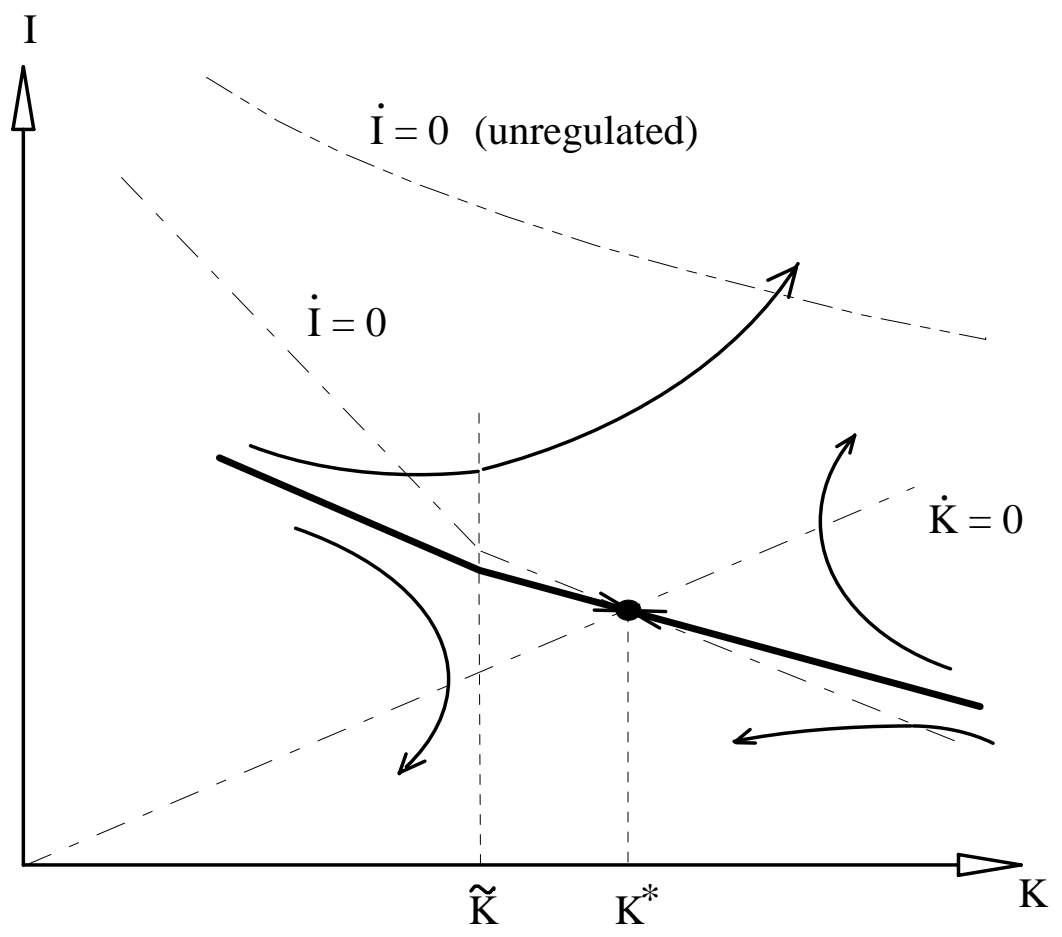

Fig. 1: Optimal solution for $\tau<\tau^{*}$. 


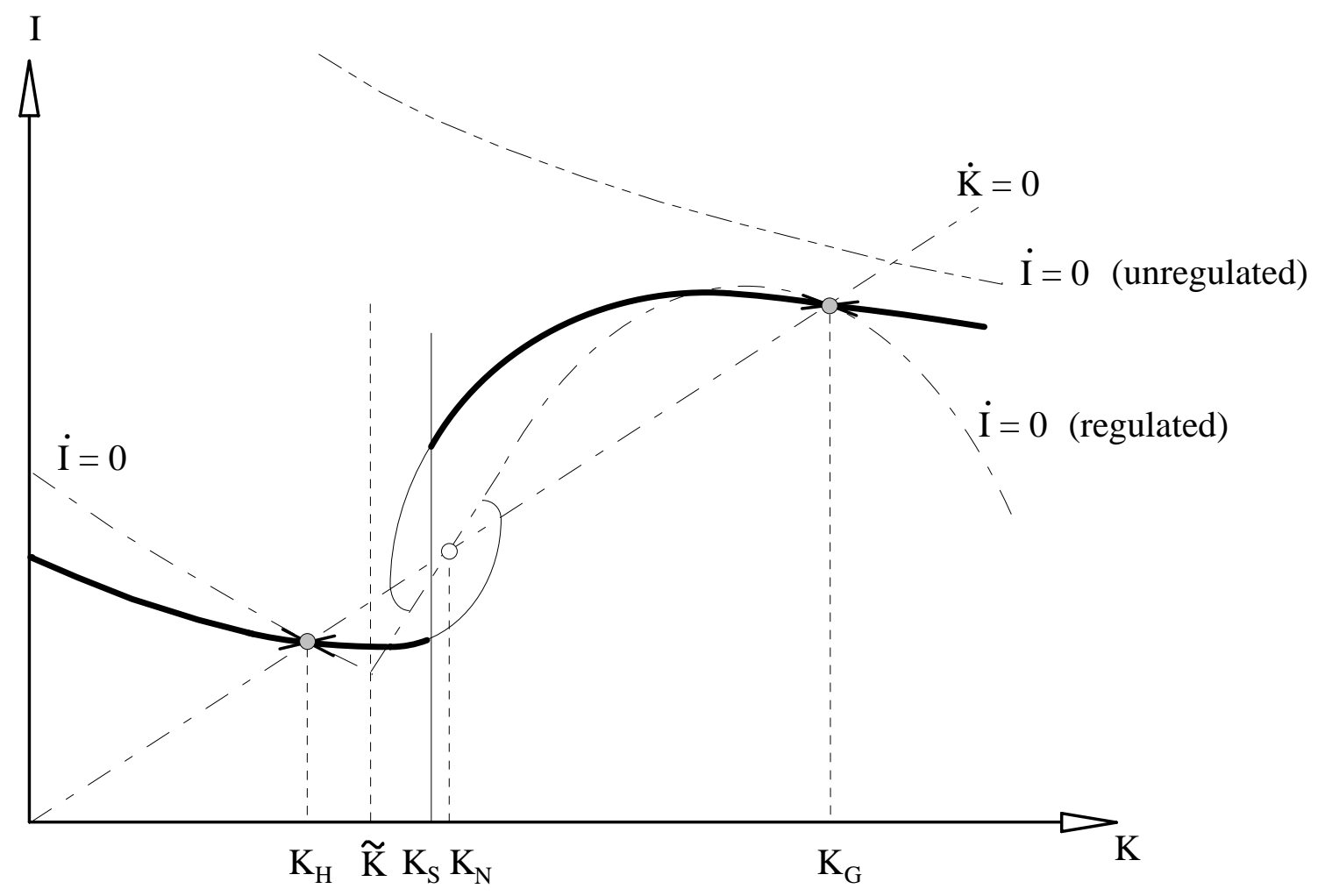

Fig. 2: Optimal solution for $\tau>\tau^{*}$. 


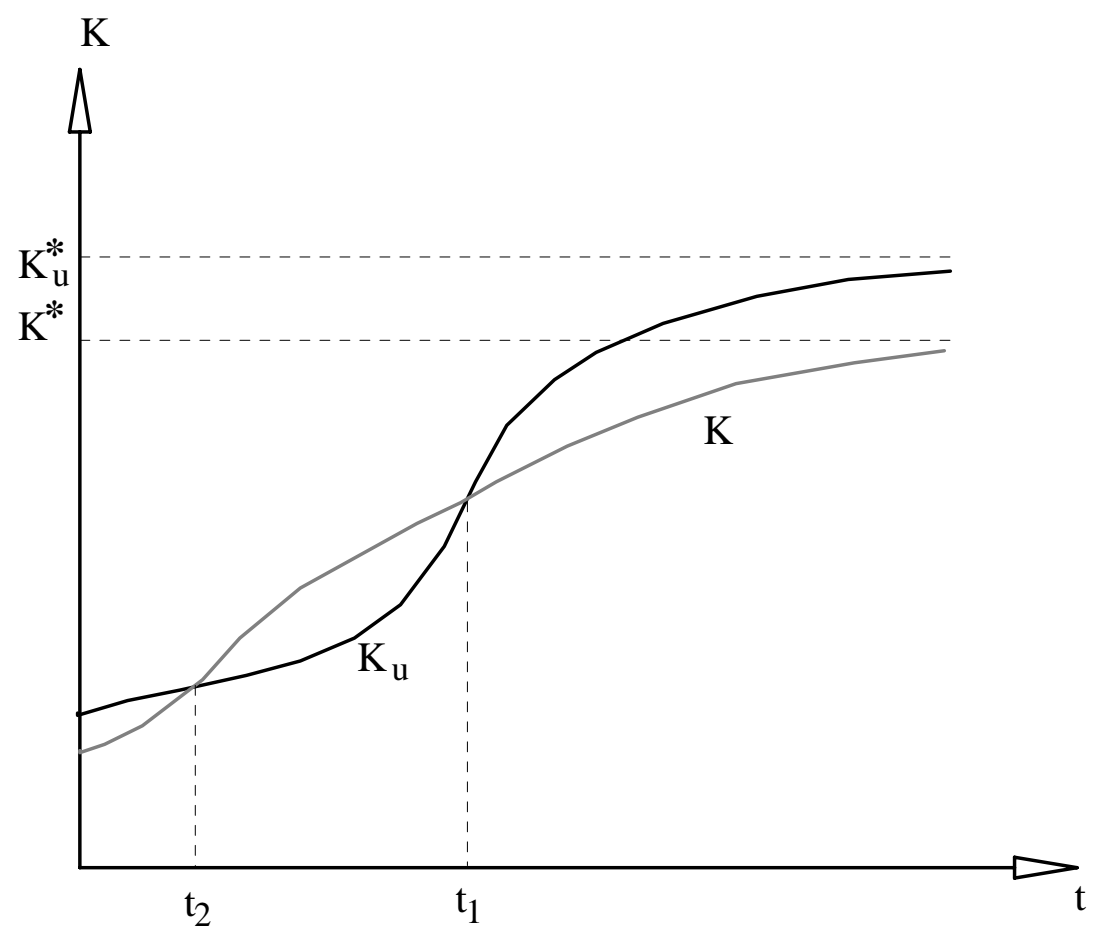

Fig. 3: Development of $K$ and $K_{u}$ in the case of existence of $t_{1}$ and $t_{2}$. 